BALJIT SIDHU

TOM SMITH

ROBERT E. WHALEY*

\title{
Regulation Fair Disclosure and the Cost of Adverse Selection
}

\begin{abstract}
Regulation FD, imposed by the Securities and Exchange Commission (SEC) in October 2000, was designed to create a level playing field by prohibiting selective disclosure of material private information to particular groups. Exactly what advantage these groups gain is unclear. If multiple insiders receive identical information, the information is immediately incorporated in price and the expected profit of each insider is zero. Regardless of the SEC's motivation in imposing Regulation FD, empirical investigation has shown that it has had a chilling effect, with firms now disclosing less information. With less information flow, private information becomes more long-lived and valuable. With increased risk of providing immediacy to informed traders, market makers will demand increased compensation, widening the bid/ask spread. To test this proposition, we identify the cost components of the bid/ask spread for a sample of NASDAQ stocks in the period just before and just after the implementation of Regulation FD. The evidence indicates that Regulation FD has led to an increase in the expected cost of the adverse selection component of the spread.
\end{abstract}

Current draft: May 17, 2004

\footnotetext{
* Sidhu is from the Australian Graduate School of Management, University of New South Wales, Sydney Australia; Smith is from the Australian National University, Canberra, Australia; and Whaley is from the Fuqua School of Business, Duke University. Comments and suggestions by Peter Clarkson, Patricia Dechow, Neil Fargher, Lynn Gallagher, Barry Oliver, and Terry Walter as well as seminar participants at the University of Queensland and the University of New South Wales Conference on Information Quality and Markets are gratefully acknowledged.
} 


\section{Regulation Fair Disclosure and the Cost of Adverse Selection}

The Securities and Exchange Commission's Selective Disclosure and Insider Trading Regulation became effective on October 23, 2000. ${ }^{1,2}$ In a section popularly referred to as Regulation Fair Disclosure (or simply "Regulation FD"), the SEC exercised its intention to create a level playing field for all investors with respect to accessing price sensitive information. Regulation FD prohibits the selective disclosure of material non-public information to exclusive groups or individuals such as investment analysts or institutional investors. If material disclosures are intended through such briefings, the same information must be disclosed simultaneously to the investing public. In the event of any inadvertent selective disclosure of material information, a public announcement is required to be made within 24 hours by filing a Form 8-K or through a medium capable of mass and unbiased distribution [see SEC (2000a)].

The motivation for imposing Regulation FD was the belief that certain members of the investment community with access to private information had a trading advantage over (and at the expense of) the wider investing public. In the past, corporate managers have used private briefings with key analysts to guide or manage earnings forecasts of analysts so as to minimize surprises and sudden price movements on earnings announcements. $^{3}$ The former SEC Chairman Levitt expressed the view that this constituted artificial smoothing and delayed the price discovery process giving undue trading advantage to a favored few and their clients [see SEC (2000a)]. He also commented that,

"...when information travels only to a privileged few, when that information is used to profit at the expense of the investing public, when that information comes by way of favored access rather than by acumen, insight, or diligence, we must ask, "Whose interest is really being served?" If investors see a stock's price change dramatically - but are given access to critical market-moving information only much later-we risk nothing less than the public's faith and confidence in America's capital markets."

Arthur Levitt, Former Chairman of SEC [see SEC (2000b)]

\footnotetext{
${ }^{1}$ See www.sec.gov/rules/final/33-7881.htm

2 See www.sec.gov/news/extra/seldisal.htm
} 
Regulation FD has been plagued by a continuing debate with respect to its desirability and efficacy. The SEC argued that Regulation FD would improve investor confidence in the integrity of the capital markets by reducing the "potential for corporate management to gain or maintain favor with particular analysts or investors” [see SEC (2000a)]. Reliance on private briefings may have compromised analysts into issuing favorable reports so to maintain access to corporate management; the new regulation would force analysts to do more independent research. The regulation would improve information flow to the market and remove the opportunity for selective recipients to trade on private information. ${ }^{4}$ Finally, implementation would not be costly given recent technological developments that facilitate rapid and mass dissemination of information.

The academic literature on market microstructure and trading strategy offers little support for the SEC's position. Holden and Subrahmanyam (1992) and Foster and Viswanathan (1996), for example, show that if there are multiple informed traders with identical information, you get a bang, bang result whereby the information is immediately incorporated into price and insiders' expected profit is zero. Hence, analysts and their clients would receive no benefit from the private briefing. Foster and Viswanathan go on to show that, if the information is not identical and not perfectly correlated, insiders can exploit the information and earn some of the potential profits-the amount depending upon the degree of correlation of the insiders information. In the case being addressed by Regulation FD, however, the analysts receive identical information at the private briefing and no exploitable profit opportunity.

Views from the investment industry regarding the desirability of Regulation FD are, at best, neutral. Before the imposition of Regulation FD, the Council of Institutional Investors (CII) expressed the view that Regulation FD would not reduce communications from corporations because

“... in order to continue attracting capital, issuers will meet the market's demand for investment information ..." [see CII (2000)].

\footnotetext{
${ }^{3}$ Richardson et al (2004) offer evidence that suggests that firms provide private information to analysts in order to manage EPS expectations downward, setting the stage for subsequently realized EPS to beat analysts' forecasts.

${ }^{4}$ Admati and Pfleiderer (1988) show that informed trading reduces market liquidity and increases price volatility.
} 
But, this is neither an argument for or against Regulation FD in the sense that it implies that the regulation will have no meaningful effect. Critics, on the other hand, were more vocal. They argued that Regulation FD would have a "chilling" effect, with firms reducing the quality and quantity of information flowing to the market. One reason is that firms prefer to release information to a selected audience rather than to the investing public at large. By constraining their audience to, say, analysts, the firm can reduce the proprietary costs of disclosure and limit the litigation risk that may arise from misinterpretation of detailed or complex information releases by less skilled users. In addition, analysts can be constrained to using private information purely to inform earnings forecasts and for no other purpose. ${ }^{5}$ Another incentive for the firm to disclose less is that they reduce the prospect of legal action against the firm by the SEC. The Association for Investment Management and Research (AIMR), for example, expressed the concern that

"Corporations will almost certainly curtail the information flow to the market to avoid having to decide on the spot whether certain information will be deemed to be material after the fact by the SEC ...." [see AIMR (2000)].

Information would tend to be released in standard or raw form with little value added in terms of management guidance. Without guidance from management (through the analyst community) with respect to interpretation, users would have to make their own inferences [see Weber (2000)].

Views from the investment industry on impact of Regulation FD since October 2000 are fairly consistent. In a recent survey, the Security Industry Association (SIA) found that 72 percent of analysts interviewed believe that information flowing to the public from corporations is now of lower quality [see AIMR (2001)]. Likewise, a March 2001 survey of AIMR members revealed that 57 percent (14 percent) of its members believed that Regulation FD had reduced (increased) the quantity of information flow to investors. Similarly, 56 percent (15 percent) believed that the quality of information had

\footnotetext{
${ }^{5}$ See Irani and Karamanou (2003) for a more detailed account.
} 
decreased (increased). Further, 71 percent stated that the reduced information flow increased market volatility. ${ }^{6}$

The survey evidence, while informative, does not measure the impact of Regulation FD on the information environment. A number of empirical studies have attempted to fill the void by examining the accuracy and dispersion of analysts' forecasts and the behavior of stock return volatility, trading volume, and/or bid-ask spreads in the months surrounding the implementation of Regulation FD. While these studies, too, are informative, they provide only indirect measures of whether there is more or less informed trading taking place. The purpose of this paper is to estimate the probability of informed trading and the cost of adverse selection in the period immediately before and immediately after the implementation of Regulation FD. We do so by examining the cost components of market maker bid/ask spreads in the NASDAQ market. The evidence suggests that, while spreads have fallen over time, the probability of informed trading and the size of the adverse selection component of the spread have risen. The outline of the paper is as follows. In the first section, we review the results of the empirical work that has focused on the effects of Regulation FD. The second section contains a description of the theoretical model, and the third section contains a description of the sample. The fourth section contains the empirical analyses and a discussion of the results. The paper concludes with a brief summary.

\section{PAST LITERATURE}

Now that Regulation FD is in effect, what was a debate surrounding its desirability has turned to empirical examination of its effectiveness. Effectiveness can be measured in a number of ways. One way is to examine whether Regulation FD has changed the disclosure environment in some manner. Have the quantity, quality, and frequency of voluntary disclosure by firms, for example, increased or decreased? Along the same line, have the accuracy and/or the dispersion of analysts' forecasts changed in a significant manner? Another way is to look for capital market effects. Have market

\footnotetext{
${ }^{6}$ In contrast, a survey by PricewaterhouseCoopers finds eighty percent of executives surveyed see a positive or neutral effect through the introduction of Regulation FD (PricewaterhouseCoopers, 2001).
} 
activity measures such as trading volume and return volatility increased or decreased? Finally, while both of the above streams of research speak to the question of whether or not Regulation FD has had a chilling effect on information releases, they do not speak directly to the issue of informed trading. If there has been a chilling effect, private information becomes more long-lived and, hence, more valuable. In such an environment, the adverse selection cost component of the bid/ask spread will increase. This third stream of research, related to ours, is directed at the effect of Regulation FD on the bid/ask spread and the probability of informed trading. Measurement of these variables is critical since it is the change in these variables that measures the degree to which the playing field has been leveled.

\section{A. Changes in the disclosure environment}

Among the first studies to have examined the effects of Regulation FD is Heflin, Subramanyam and Zhang (2003a). They focus on three issues: (a) the accuracy and dispersion of analysts' earnings forecasts, (b) the frequency of firms' voluntary disclosures, and (c) the informational efficiency of stock prices prior to firms' earnings announcements. The intuition underlying the use of analyst forecasts is that the curtailment of analysts' privileged access to management guidance may reduce the accuracy and increase the dispersion of their forecasts. ${ }^{7}$ Their evidence suggests that there has been no significant change in analyst forecast accuracy or dispersion. The motivation for examining voluntary disclosures is that some critics argued that Regulation FD would cause management to be less forthcoming with information due to factors such as increased litigation risk. Here, they find a significant increase in the frequency of voluntary public disclosures after Regulation FD. Finally, on the issue of informational efficiency, they measure "information gap" (i.e., the absolute deviation in stock price between various pre-earnings-announcement days and the post-earningsannouncement day after controlling for market wide movements ${ }^{8}$ ) both before and after Regulation FD came into effect and find no evidence that information available to the

\footnotetext{
${ }^{7}$ In related work, Brown, Taylor, and Walter (1999) examine the accuracy of forecasts before and after sanctions placed on firms that did not comply with Australian Stock Exchange requirements.

${ }^{8}$ Specifically, they measure absolute cumulative abnormal return from 64 days before to 2 days after an earnings announcement. The smaller the "information gap," the greater the information available to the market pre-announcement.
} 
market prior to earnings announcements had deteriorated after Regulation FD. If anything, the evidence suggests that the information gap between pre- and postannouncement price has become smaller since the introduction of Regulation FD.

Other studies focusing on the accuracy and dispersion of analyst forecasts include Agrawal and Chadha (2002), Mohanram and Sunder (2001) and Shane et al (2001). Unlike Heflin et al (2003a), these studies report that analysts' forecasts have been less accurate and have had higher dispersion ${ }^{9}$ in the post-FD period. Shane et al (2001) add that deterioration in forecast accuracy in the post-FD period tends to be true for forecasts issued earlier in the quarter as opposed to those issued later in the quarter. In other words, shorter-term forecasts do not suffer deterioration in accuracy. Meanwhile Mohanram and Sunder (2001) report analysts who were ranked as All-Stars (superior analysts) were less affected and that there was also a greater importance placed on idiosyncratic information search and analysis in the post-FD period. They assert superior analysts are, therefore, more likely to differentiate themselves in the post-FD environment and that the regulation has not negatively impacted on analysts’ incentives to gather information.

\section{B. Changes in trading behavior}

The effects of Regulation FD on stock return volatility and trading volume have also been examined. The intuition here is with continuous and complete information flow, stock prices adjust quickly and accurately to their fair values. A move toward providing more continuous and complete information to market participants will result in lower stock return volatility and higher trading volume, and vice versa.

The empirical evidence regarding the effect of Regulation FD on return volatility is mixed. Heflin et al (2003b), Gadarowski and Sinha (2002), and Shane et al (2001) find a significant decrease in return volatility after Regulation FD. While on face appearance this seems to support position that there was an improvement in the information environment, these assessments fail to account for the reduction in the minimum tick size from sixteenths to decimal that occurred during the investigation periods. Bailey et al

\footnotetext{
${ }^{9}$ Irani and Karamanou (2003) and Bailey et al (2003) also report an increase in forecast dispersion after Regulation FD.
} 
(2003) correct for this problem and find no significant change in return volatility. Similarly, Eleswarapu et al (2002) finds no change.

Bailey et al (2003) also examine trading volume before and after the implementation of Regulation FD. They report a significant increase in trading volume in the post-Regulation FD period after controlling for the effects of decimalization. They attribute the increase to differential informed judgment or difference in opinion.

\section{Changes in bid/ask spread and the probability of informed trading}

Perhaps the most direct measure of information asymmetry used in the empirical literature to date is the market maker's bid/ask spread. The bid/ask spread is a function of order processing costs, inventory-holding costs, adverse selection costs, and competition. To the extent that order processing costs, inventory-holding costs, and competition among market makers are unaffected by Regulation FD, a change in spread must be driven by a change in adverse selection costs. Sunder (2002) uses relative bid-ask spread as a proxy for the level of information asymmetry between informed and uninformed traders of firms using conference calls to communicate. In the pre-FD period, he finds firms disclosing information through "restricted" conference calls had higher bid-ask spreads (higher information asymmetry) than firms that used "open” conference calls. ${ }^{10}$ These differences do not persist in the post-FD period, however. Based on this evidence, he concludes that the playing field has been leveled. Unfortunately, Sunder's regression model does not explicitly isolate the information asymmetry cost component of the bid/ask spread. His results can be driven by cross-sectional variation in any cost component of bid/ask spread including order processing costs, inventory-holding costs, and competition. In addition, the use of relative spread in a regression model that includes an intercept is problematic.

Eleswarapu et al (2003) proxy information asymmetry using the relative bid-ask spread but include a measure of the order flow imbalance in the manner of Huang and Stoll (1996). Using data on trading days surrounding earnings-related announcements, they find a reduction in information asymmetry after the introduction of Regulation FD,

\footnotetext{
${ }^{10}$ Firms using 'restricted' conference calls made their calls available to analysts and institutional investors only while those using ‘open’ calls always held calls accessible to all investors.
} 
with the reduction being most noticeable in less liquid firms. Strasser (2002) uses two measures of information asymmetry: (a) the probability of informed trading based on Easley, Keifer, O’Hara and Paperman (1996); and (b) the adverse selection component of the spread derived from a modified version of Huang and Stoll (1997). He finds that both approaches show that the probability of informed trading does not change significantly between the pre- and post-FD periods. Aslan (2003) also uses the Easley et al (1996) model and concludes that the probability of informed trading has decreased for medium and large firms but has increased for small firms. Unfortunately, these approaches depend on theoretical models that assume that the only time-series variation in spread is driven by informational asymmetry. Temporal movements in order processing costs, inventoryholding costs, and competition are assumed away by fiat. Without explicitly modeling the effects of these variables, the results must be interpreted cautiously.

\section{MODEL}

In order to assess the probability and expected cost of informed trading in the preand post-Regulation FD periods, a formal model of the market maker's bid/ask spread is necessary. Such a model must identify all of the components of the spread including minimum tick size, order processing costs, inventory-holding costs, asymmetric information costs, and competition. It must also be straightforward to estimate. To this end, we adopt the bid/ask spread regression model developed in Bollen, Smith and Whaley (2004) (hereafter "BSW"). This section has three parts. In the first, we describe a simple version of the BSW regression model to illustrate the underlying economic intuition regarding its structure. In the second, we present the full-blown model that explicitly specifies (and allows us to estimate) the probability and the expected cost of informed trading. Finally, we explain how the model can be used to identify incremental costs arising from a market intervention such as the SEC's Regulation FD.

\section{A. Components of bid/ask spread}

The first regression model developed in BSW has the specification,

$$
S P R D_{i}=\alpha_{0}+\alpha_{1} \operatorname{InvTV}_{i}+\alpha_{2} M_{H I}+\alpha_{3} I H P_{i}+\varepsilon_{i},
$$


where $S P R D_{i}$ is the bid/ask spread of stock $i, \operatorname{InvTV}_{i}$ is the inverse of trading volume, $M H I_{i}$ is the modified Herfindahl index, and $I H P_{i}$ is the inventory-holding premium. In this model, the specific components of the bid/ask spread are $\alpha_{0}$, the minimum tick size; $\alpha_{1} I n v T V_{i}$, order processing costs; $\alpha_{2} M H I_{i}$, competition; and $\alpha_{3} I H P_{i}$, the sum of the inventory holding and informational asymmetry components of the spread. The rationale for each variable on the right-hand side of the regression (1) is described in turn.

The first term on the right-hand side of (1), $\alpha_{0}$, is the exchange-mandated minimum tick size. It serves as the lower bound on the bid/ask spread. For actively traded securities with highly competitive markets, the values of all three regressors on the right hand side of Eq. (1) are near or at zero, and the bid/ask spread equals the intercept term $\alpha_{0}$ (the stock's minimum price increment). The second term models the effects of orderprocessing costs (e.g., the exchange seat, floor space rent, computer costs, informational service costs, labor costs, and the opportunity cost of the market maker's time). Because these costs are largely fixed, at least in the short run, their contribution to the size of the bid/ask spread should fall with trading volume; that is, the higher the trading volume, the lower the bid/ask spread. ${ }^{11}$ The third term captures the effects of competition among market makers. Of the proxies used in past research, the Herfindahl index makes the most sense in that it accounts for the number of market makers in a particular stock as well as the relative activity of each market maker. In its raw form, the Herfindahl index has a range from $1 / N M_{i}$ (perfect competition) to 1 (single monopolist), where $N M_{i}$ is the number of market makers. We create and apply a modified version of the Herfindahl index,

$$
M H I_{i}=\frac{H I_{i}-1 / N M_{i}}{1-1 / N M_{i}} .
$$

\footnotetext{
${ }^{11}$ To some degree, however, this relation may be weakened by the fact that market makers often make markets in more than one security. In such cases, fixed order-processing costs can be amortized over total trading volume across securities. In addition, in a highly competitive market, bid/ask spreads should equal the expected marginal cost of supplying liquidity, in which case order-processing costs may be irrelevant.
} 
$\mathrm{MHI}_{i}$ has a range from zero to one, thereby permitting the coefficient of $\mathrm{MHI}_{i}$ in our regression model Eq. (1) to have a more natural interpretation; that is, where $M H I_{i}=1$, the coefficient is an estimate of the rent per share being charged by a monopolistic market maker, and where $M H I_{i}=0$, the rent is zero.

The fourth term on the right-hand side of (1) is the market maker's "inventoryholding premium." This premium is demanded by the market maker to cover the expected cost of accommodating a customer order and then having the stock price move against him, independent of whether the trade is initiated by an informed or an uninformed customer. Assuming that the market maker sets his inventory-holding premium (IHP) component of the bid/ask spread such that he minimizes the risk of losing money should the market move against him, his demanded compensation will be

$$
I H P=-E(\Delta S \mid \Delta S<0) \operatorname{Pr}(\Delta S<0) .
$$

According to Eq. (3), the minimum IHP equals the expected loss on the trade conditional on an adverse stock price movement times the probability of an adverse stock price movement.

For implementation purposes, it is useful to note that the value of the inventoryholding premium given by the expression on the right hand-side of Eq. (3) equals the value of an at-the-money option with expiration given by the time that the stock is held in inventory. Under the Black and Scholes (1973) and Merton (1973) (hereafter, BSM) option valuation framework, the expected inventory-holding premium may be written

$$
I H P=S N\left(\frac{\ln (S / X)}{\sigma \sqrt{t}}+.5 \sigma \sqrt{t}\right)-X N\left(\frac{\ln (S / X)}{\sigma \sqrt{t}}-.5 \sigma \sqrt{t}\right)
$$

where $S$ is the true stock price at the time at which the market maker opens his position, $X$ is the exercise price of the option, $\sigma$ is the standard deviation of security return, $t$ is the time until the offsetting order, and $N(\cdot)$ is the cumulative unit normal density function. ${ }^{12}$ Since the time until an offsetting order arrives is assumed to be small, the

\footnotetext{
12 The inventory-holding premium may also be valued using the put valuation formula, which leads to identical results.
} 
interest rate term in the BSM model is ignored. Eq. (4) can be further simplified by acknowledging the fact that the option is at-the-money, in which case the inventoryholding premium is simply

$$
I H P=S[2 N(.5 \sigma \sqrt{t})-1]
$$

The difficulty in valuing the expected inventory-holding premium using Eq. (5) is that the market maker, at the time of trade, does not know when an offsetting transaction will occur. The BSM model does not apply to options with stochastic times to expiration. Fortunately, all is not lost. BSW show that IHP is approximately linear in $\sqrt{t}$. If such is the case, the expected inventory-holding premium may be written

$$
E(I H P)=S[2 N(.5 \sigma E(\sqrt{t}))-1]
$$

where $E(\sqrt{t})$ is the expected value of the square root of the time between offsetting trades. This expectation is easily estimated using transaction data and is the only aspect of the distribution of arrivals that is necessary to approximate expected $I H P$.

To summarize, in estimating Eq. (1), the coefficient $\alpha_{1}$ is expected to be positive and may be large. After all, it represents the market maker's total order-processing costs. If the market is extremely competitive, however, the market maker may not have the ability to recover fixed costs, in which case the coefficient will be indistinguishably different from zero. ${ }^{13}$ The coefficient $\alpha_{2}$ should be positive. The fewer the number of dealers and the less evenly distributed the trading volume across dealers, the higher the modified Herfindahl index and the higher the spread. The coefficient $\alpha_{3}$ should also be positive. The higher the expected inventory-holding premium, the greater the bid/ask spread. In this initial specification, $I H P_{i}$ is estimated as a single at-the-money option, with no distinction drawn between informed and uninformed traders. With a precise estimate of the expected length of market maker's holding period, the coefficient value should be one. 


\section{B. Informed versus uninformed traders}

A market maker will demand different inventory-holding premia for trades with informed and uninformed traders. Assume that the market maker currently has no inventory, and a trader steps forward and buys at the market maker's posted ask price, $S_{\text {ask }}$. The market maker, now short a share of stock, is concerned about his expected loss should the share price increase. If the trader is uninformed $(U)$, the expected inventoryholding premium, $I H P_{U}$, equals the value of a slightly out-of-the-money call option with an exercise price equal to $S_{\text {ask }}$. Presumably the true price of the underlying stock is somewhere between the bid and ask price quotes. If the trader is informed (I), the true price of the stock rests somewhere above the ask price, in which case the expected inventory-holding premium, $I H P_{I}$, equals the value of a slightly in-the-money call. In either case, the valuation of the IHP is

$$
I H P_{i}=S_{i} N\left(\frac{\ln \left(S_{i} / X\right)}{\sigma \sqrt{t}}+.5 \sigma \sqrt{t}\right)-X N\left(\frac{\ln \left(S_{i} / X\right)}{\sigma \sqrt{t}}-.5 \sigma \sqrt{t}\right)
$$

where $i=U, I$ depending upon whether the trade was with an uninformed or an informed trader.

From the market maker's perspective, the required inventory-holding premium, $I H P$, equals the sum of the expected inventory-holding cost and expected adverse selection cost components of the spread, that is,

$$
I H P=\left(1-p_{I}\right) I H P_{U}+p_{I} I H P_{I},
$$

where $p_{I}\left(1-p_{I}\right)$ is the probability of an informed (uninformed) trade. To illustrate the tradeoff between the required costs of uninformed and informed trades, consider the following illustration. Ignoring all factors influencing the bid/ask spread except the inventory-holding premia, the spread equals the sum of the expected costs of trading with uninformed and informed traders, that is,

\footnotetext{
${ }^{13}$ In the empirical tests that follow, total trading volume across dealers, not trading volume for a particular dealer, is used in the cross-sectional regressions. This, too, downward biases the estimate of $\alpha_{1}$.
} 


$$
S P R D=\left(1-p_{I}\right) I H P_{U}+p_{I} I H P_{I}
$$

To value the inventory-holding premium for the uninformed trader, $I H P_{U}$, we value a slightly out-of-the-money call option. The true stock price is set equal to the midpoint of the bid/ask spread, and the exercise price is set equal to the ask price. ${ }^{14}$ The bid/ask midpoint is $\$ 27.50$, the bid/ask spread is $\$ .10$, and the volatility rate of the stock is fifty percent. To value the inventory-holding premium for the informed trader, $I H P_{I}$, we need to compute option values over a range of "true" stock prices since the true stock price is unobservable. Stock prices ranging from one percent to ten percent in excess of the exercise price are used. The average time between offsetting trades is allowed to vary between five minutes and thirty minutes. Based on these assumptions, the probability of an informed trade conditional on the amount of information (i.e., the degree to which $I H P_{I}$ is in the money) and the time between offsetting trades is computed. These results are reported in Table 1 . Where the true price is only slightly above the ask price, the probability of an informed trade is high. Conversely, where the true price exceeds the exercise price by a large amount, the probability of an informed trade is low. The inverse relation between these variables in each column of the table reflects the fact that, for a given time between trades, $I H P_{U}$ is constant. Assuming the spread is also constant, the probability of an informed trade must vary inversely with $I H P_{I}$.

Another feature of the inventory-holding premium (7) is worth noting. First, the expected IHP does not go to zero as the time between offsetting trades goes to zero. To see this, consider the market maker's demanded compensation for the two types of traders. If the market is highly active (i.e., $t \rightarrow 0$ ), the market maker will not require compensation for the inventory-holding costs of the uninformed trader since the position acquired from providing the market with immediacy is immediately unwound (i.e., the inventory-holding premium of an uninformed trade $I H P_{U}$ goes to zero as $t \rightarrow 0$ because the option is out of the money). The inventory-holding premium of an informed trade, $I H P_{I}$, however, approaches the dollar amount the option is in the money (i.e., the

\footnotetext{
${ }^{14}$ Given the symmetry of the problem, the illustration considers only trades at the ask. A complementary analysis can be conducted using a slightly out-of-the-money put whose exercise price equals the bid price.
} 
difference between the true price and the ask price in the case of a buy, and the difference between the bid price and the true price in the case of a sell). This result, too, is intuitive. In a highly active market, the market maker immediately realizes the full cost of providing immediacy to an informed trader. Thus, when the time between offsetting trades is zero, the market maker's demanded compensation is $I H P=p_{I} I H P_{I}$.

Another way of viewing the market maker's inventory-holding premium is

$$
I H P=I H P_{U}+p_{I}\left(I H P_{I}-I H P_{U}\right)
$$

Eq. (9) says that an expected inventory-holding premium of $I H P_{U}$ exists for all trades, uninformed and informed alike, as a result of the price risk associated with having the security in inventory. For informed trades, however, there is an incremental expected cost is associated with adverse selection, that is, $p_{I}\left(I H P_{I}-I H P_{U}\right)$. The structure of Eq. (9) also provides a means of estimating the probability of informed trades, as we will see shortly.

Before focusing specifically on estimating the probability of informed trading, we need to address a subtle issue. In estimating the inventory-holding premium, we use the average time between trades as a proxy for the market maker's expected holding period. Because trades appearing in the data base are executed by many market makers, our proxy understates the length of the holding period. To estimate the length of the holding period across market makers, we set the coefficient $\alpha_{3}$ to one in Eq. (1) and estimate the length of the holding period $\tau_{i}$ by scaling each individual stocks average square root of time between trades by a constant factor. The regression specification is

$$
\operatorname{SPRD}_{i}=\alpha_{0}+\alpha_{1} \operatorname{InvTV}_{i}+\alpha_{2} \mathrm{MHI}_{i}+\operatorname{IHP}{ }_{i}\left(\tau_{i}\right)+\varepsilon_{i} .
$$

Finally, with the time between trades, $\tau_{i}$, set so as to create a coefficient value equal to one, we can estimate the probability of informed versus uninformed trades across stocks. In Eq. (9), we showed that the inventory-holding premium consists of a common expected cost across trades, $I H P_{U}$ plus an incremental expected cost associated with 
informed trades, $p_{I}\left(I H P_{I}-I H P_{U}\right)$. Substituting Eq. (9) into Eq. (10) provides the regression specification,

$$
S P R D_{i}=\alpha_{0}+\alpha_{1} \operatorname{InvTV}_{i}+\alpha_{2} M H I_{i}+I H P_{U, i}\left(\tau_{i}\right)+\alpha_{4}\left(I H P_{I, i}\left(\tau_{i}\right)-I H P_{U, i}\left(\tau_{i}\right)\right)+\varepsilon_{i},
$$

where the coefficient $\alpha_{4}$ represents the probability of an informed trade. Specifying the regression in this manner has two important advantages. First, it removes a serious collinearity problem that would likely exist between $I H P_{I, i}$ and $I H P_{U, i}$. Second, it allows us to test the null hypothesis that the probability of an informed trade is equal to zero.

\section{Incremental effects due to Regulation FD}

To assess whether Regulation FD affected the probability and expected cost of informed trading, we need to allow for the fact the any of the factors affecting bid/ask spread may have changed from the pre- to the post-FD periods. To do so, we re-specify Eq. (11) in a way that allows all components to change, that is,

$$
\begin{aligned}
S P R D_{i}= & \alpha_{0}+\alpha_{1} \operatorname{InvTV}_{i}+\alpha_{2} M H I_{i}+\alpha_{3} I H P_{U, i}\left(\tau_{i}\right)+\alpha_{4}\left(\operatorname{IHP}_{I, i}\left(\tau_{i}\right)-I H P_{U, i}\left(\tau_{i}\right)\right) \\
& +\alpha_{5} d_{t}+\alpha_{6} \operatorname{InvTV}_{i} d_{t}+\alpha_{7} M H I_{i} d_{t}+\alpha_{8} I H P_{U, i}\left(\tau_{i}\right) d_{t}+\alpha_{9}\left(I H P_{I, i}\left(\tau_{i}\right)-I H P_{U, i}\left(\tau_{i}\right)\right) d_{t}+\varepsilon_{i}
\end{aligned}
$$

In Eq. (12), the $d_{t}$ is a dummy variable that takes on a value of 0 before Regulation FD was imposed and 1 afterward. The coefficients $\alpha_{5}$ through $\alpha_{9}$ measure incremental effects: $\alpha_{5}$ is the shift in the minimum spread, $\alpha_{6}$ is the shift in order processing costs, $\alpha_{7}$ is the shift in the effect of order processing costs, and $\alpha_{8}$ is the shift in inventoryholding costs. The effects of Regulation FD on informed trading are captured in the coefficient $\alpha_{9}$. The coefficient $\alpha_{9}$ is the change in the probability of informed trading, and the product $\alpha_{9}\left(I H P_{I, i}\left(\tau_{i}\right)-I H P_{U, i}\left(\tau_{i}\right)\right)$ is the change in the expected cost of market makers trading with informed customers. Eq. (12) provides the framework for our empirical assessments in Section IV.

\section{DESCRIPTION OF SAMPLE AND SPREAD ESTIMATION}

Measuring the effects of Regulation FD is complicated by the fact that the stock market was in transition in the months surrounding October 2000. In particular, the New York Stock Exchange had begun to switch from sixteenths to decimal pricing in August 
2000, two months before the enactment of Regulation FD. The transition was not completed until January 2001, three months after. This change in minimum tick size complicates matters in the sense that it reduces our ability to accurately measure the bid/ask spread and its components. ${ }^{15}$ To avoid the confounding effects of decimalization, we focus on NASDAQ stocks. For NASDAQ stocks, the change to decimal pricing did not occur until April 9, 2001. ${ }^{16}$ We define the pre-Regulation FD period to be the five months before the implementation of the rule in October 2000 (i.e., May 2000 through September 2000) and the post-Regulation FD period to be the five months after but before decimal pricing (November 2000 through March 2001). The use of NASDAQ stocks has the additional advantage that monthly information on the number of market makers for each stock is available. Historical files containing the number of dealers making markets on NASDAQ as well as their respective trading volumes are available on a monthly basis on www.Nasdaqtrader.com.

The trade and quote data used in this study were downloaded from NYSE's Trade and Quote (TAQ) data files. For all time-stamped trades on TAQ, we matched the quotes prevailing immediately prior to the trade. From this matched file, we then computed six summary statistics for each stock each day: (a) the number of trades, (b) the end-of-day share price (the last bid/ask midpoint prior to 4:00 p.m. EST), (c) the number of shares traded, (d) the equal-weighted quoted spread, (e) the volume-weighted effective spread, and (f) the average of the square root of the time between trades.

To test the robustness of our results, we compute two measures of spread. The first is quoted spread, that is,

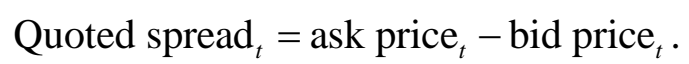

We measure equal-weighted quoted spread (EWQS) as the arithmetic average of the prevailing quoted spreads at the time of each transaction $t$ of a particular stock during the trading day. The second is the effective spread. The effective spread is based on the

\footnotetext{
${ }^{15}$ Bailey et al (2003) argue studies documenting a reduction in return volatility in the post-FD period is attributable to the move to decimal pricing.

${ }^{16}$ Fifteen NASDAQ stocks began trading in decimal on March 12, 2001, with an additional 177 stocks beginning March 26, 2001. The remaining 4,650 stocks were converted to decimal pricing on April 9, 2001.
} 
notion that the trade is only costly to the investor to the extent that the trade price deviates from the true price, approximated by the bid/ask price midpoint,

$$
\text { Midpoint }_{t}=\frac{\left(\text { bid price }_{t}+\text { ask price }_{t}\right)}{2} \text {. }
$$

On a round-turn, the cost would be incurred twice, hence the measure of the effective spread is

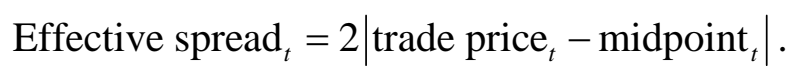

Note that if all trades take place at the prevailing bid and ask quotes, the effective spread equals the quoted spread. If some trades take place within the spread, the effective spread is smaller than the quoted spread. The volume-weighted effective spread (VWES) is a volume-weighted average of the effective spreads of the trades occurring throughout the day.

With the six summary statistics compiled for each stock each day, we compute average values for each stock across all days in the month. To mitigate the effects of outliers, we constrain the sample to include only stocks whose shares traded at least five times each day every day during the month.

Three additional measures are then appended to each monthly stock trade record. First, the modified Herfindahl index is computed. This competition measure incorporates the numbers of dealers making a market as well as their respective trading volumes. Second, the rate of return volatility for each stock is computed using daily returns over the sixty trading days preceding the sample month. The returns were obtained from the Center for Research in Security Prices daily return file, and the daily return standard deviation was annualized using the factor $\sqrt{252}$. Finally, the inventory-holding premium for each stock is computed using Eq. (5), where $S$ is the stock's average share price, $\sigma$ is the annualized return volatility, and $E(\sqrt{t})$ is the average of the square root of the time between trades. ${ }^{17}$ With more than one market maker, this estimate understates the

\footnotetext{
${ }^{17}$ Because volatility is expressed on an annualized basis, the time between trades must be measured in years. To accomplish this task, we divide the number of minutes between trades by 390 (the number of minutes in a trading day) and then by 252 (the number of trading days in a year).
} 
expected inventory-holding premium. If trading volume was uniformly distributed across all dealers, we could multiply the average by the number of dealers. But, this value would cause inventory-holding premiums to be overstated, because only a handful of dealers account for the lion's share of the trading volume of a stock. We later allow the data to infer the square root of the average time between trades. ${ }^{18}$

\section{EMPIRICAL RESULTS}

The analyses provided in this section have four parts. First, we examine descriptive statistics for the bid/ask spread and its determinants in the sub-period before and after Regulation FD became effective. Second, we compare the performance of the simplified version of the BSW regression model with an ad hoc model based on past research. Third, we estimate the change in the expected cost of informed trading. Finally, we partition the effective bid/ask spread into its basic cost components.

\section{A. Descriptive statistics}

Table 2 contains summary statistics of the bid/ask spreads of the stocks included in the sample. Also included are summary statistics of the spread determinants. The table contains a number of interesting results. The bid/ask spread measures, for example, drop significantly from the first sub-period to the second. The volume-weighted quoted spread is 13.23 cents on average during the pre-Regulation FD sub-period and is 11.43 cents afterward. One possible explanation for this result is that Regulation FD lowered the information asymmetry cost component of the bid/ask spread. Another is that the order processing cost per share fell as a result of the 48 percent increase in average daily trading volume from 450 thousand shares in the first sub-period to 668 thousand in the second. Yet another is that the market making in NASDAQ stocks became more competitive. Although the average number of dealers per stock falls from 89 in the first sub-period to 79 in the second, the average value of the Herfindahl index falls from .1194 to .1076 . The fact that there are competing explanations for the reduction in spread shows

\footnotetext{
${ }^{18}$ Another approach is to infer the equivalent number of independent market makers by using the modified Herfindahl index. 1-MHI is the proportion of market makers who are competitive. Multiplying the average
} 
the danger in using changes in the level of the bid/ask spread as a gauge of whether Regulation FD was effective. In order to make such an assessment, the cost components of the spread must be separated.

The descriptive statistics in Table 2 also suggest that other components of the spread have also changed. The reduction in share price from the first sub-period to the second suggests that inventory-holding costs have fallen. On the other hand, the return volatility of stocks has increased on average, which means inventory-holding costs may have increased.

\section{B. Regression results using at-the-money option to value inventory-holding premium}

Table 3 contains a summary of the preliminary regression results. All of the $t$ ratios are corrected for heteroskedasticity and autocorrelation in the residuals. Panel A (Panel B) contains the results for the regressions that use equal-weighted quoted spread (volume-weighted effective spread) as the dependent variable. The first three rows in each panel are the results of the BSW model when an at-the-money option is used to value the inventory-holding premium. See Eq. (1). The second three rows contain the results of an ad hoc spread regression of the type used in past work. The ad hoc regression specification is

$$
S P R D_{i}=\alpha_{0}+\alpha_{1} \operatorname{InvTV}_{i}+\alpha_{2} M_{H} I_{i}+\alpha_{3} S_{i}+\alpha_{4} \sigma_{i}+\alpha_{5} \bar{t}_{i}+\varepsilon_{i},
$$

and is intended to serve as a benchmark with which to judge the effectiveness of the BSW model.

The results shown in Panel A of Table 3 indicate that all cost components are important determinants of the quoted bid/ask spreads. The single most important explanatory variable appears to be the inventory-holding premium. Its coefficient estimate is greater than one, indicating that, as expected, the average time between trades is a downward biased estimate of the expected length of the market maker's holding period. ${ }^{19}$ The sign and the significance of the coefficient $\alpha_{2}$ indicates that competition

time between trades by 1-MHI and then by the number of market makers should produce the average time between trades for a typical market maker.

19 Later in this section, we allow the data to identify the average of the square root of the time between trades. 
among market makers also plays an important role in determining the absolute level of the bid/ask spread. The higher the modified Herfindahl index (the lower the competition), the greater the spread. The coefficient estimate of 0.0525 in the post-Regulation FD subperiod, for example, implies that the quoted bid/ask spread will be 5.25 cents higher in a market with a monopolist than a market with perfect competition. The coefficient of competition in the first sub-period is positive but insignificant. The inverse of trading volume also enters significantly. Its magnitude is much smaller in the second sub-period than in the first, indicating perhaps that the fixed cost per share of market making has fallen. Finally, recall that our model Eq. (1) is structured so that the level of the intercept term equals the minimum tick size. The estimate of the intercept term $\alpha_{0}$ in the first-subperiod is 0.0517 , which is slightly less than the exchange-mandated 0.0625 (onesixteenth). The intercept is 0.0419 in the second sub-period.

The first three rows of Panel B contain the regression results when volumeweighted effective spread is used instead of equal-weighted quoted spread as the dependent variable. Because many trades take place within the prevailing price quotes, effective spread is a more accurate measure of market maker revenue. Like in the quoted spread regression, expected inventory-holding premium has the greatest explanatory power. The expected inventory-holding premium coefficient estimate is less than it was for the quoted spread. Still, it remains considerably higher than its theoretical value of one. The intercept estimates are lower than the regression for quoted spread. This is not surprising given that the effective spread can have values as low as zero. ${ }^{20}$ The estimate, 0.0412 in the first sub-period, for example, represents the level of revenue per share that the market maker can expect to earn for providing liquidity in an extremely active stock. The estimate in the second sub-period is 0.0347 , showing that the level of spread for active stocks has fallen.

The second three rows in each panel of Table 3 illustrate what can happen when the determinants of spread are specified in an ad hoc fashion. In place of using the BSW model, we include share price, return volatility, and the average time between trades (the

\footnotetext{
${ }^{20}$ The effective spread equals zero in instances in which the quoted spread is an even number of ticks and the trade takes place at the midpoint.
} 
determinants of the inventory-holding premium) together with the inverse of trading volume and the modified Herfindahl index as the determinants of spread. Furthermore, suppose we assume the relation is linear, as is done in some of the past studies.

The results reported for the ad hoc regression are striking in a number of ways. First, the order-processing cost component of spread increases dramatically. This is curious considering the significant increase in trading volume post-Regulation FD. Second, while the coefficient of share price is significant and has its expected sign, the coefficient of return volatility is insignificant and the coefficient of the average time between trades is significant but has the wrong sign. Third, the adjusted R-squared levels in the ad hoc regression are dramatically less than for the BSW model (e.g., 0.4029 in the first sub-period for the ad hoc regression versus 0.7772 for the properly specified model). These results emphasize the importance of model specification. Although both regressions contain the same independent variables, knowing the proper variable definitions and model structure substantially improves performance.

\section{Estimating the probability and expected cost of informed trades}

We now turn to estimating the probability and expected cost of informed trading. As a preliminary investigation, we estimate the regression model,

$S P R D_{i}=\alpha_{0}+\alpha_{1} \operatorname{InvTV}_{i}+\alpha_{2} M H I_{i}+\alpha_{3} I H P_{i}+\alpha_{4} d_{t}+\alpha_{5} \operatorname{InvTV}_{i} d_{t}+\alpha_{6} M H I_{i} d_{t}+\alpha_{7} I H P_{i} d_{t}+\varepsilon_{i}$

where $d_{t}$ is a dummy variable whose value is 0 in months preceding October 2000 and 1 in months after October 2000. The coefficients $\alpha_{4}$ through $\alpha_{7}$, therefore, measure changes in the cost components of the bid/ask spread resulting from the implementation of Regulation FD. Panel A of Table 4 contains the results. For the most part, the cost components do not appear to have been affected by Regulation FD, with no significant changes reported for minimum tick size $\alpha_{4}$, order processing $\operatorname{costs} \alpha_{5}$, and inventoryholding premium $\alpha_{7}$. The only variable whose coefficient changed significantly is competition $\alpha_{6}$. One possible explanation for this result is that market makers in less competitive markets increased spreads post-Regulation FD to compensate for the increased prospect of informed trading. In more competitive markets, this may not have been possible. 
To further isolate the effect of informed trading on the bid/ask spread, we focus on the components of inventory-holding premium. Recall that the inventory-holding premium, as modeled in Eq. (1), incorporates the trades of both uninformed and informed traders. While the results in Panel A show no change in the contribution of IHP to the bid/ask spread, it is possible that the informed trader $I H P_{I}$ changed in one direction and the uninformed trader $I H P_{U}$ in the other. To test this proposition, we substitute Eq. (9) into the regression model. In place of using a single at-the-money option to value the inventory-holding premium, we use an out-of-the-money option value for uniformed trades and an in-the-money option for informed trades. Valuing the out-of-the-money option, we assume that the true stock price is the midpoint between the bid and ask prices and that the exercise price is the bid or the ask depending on whether the customer's trade was a sale or a purchase. To value the in-the-money option, however, is more difficult. While we know the option's exercise price (i.e., the ask price on a customer purchase and the bid price on a customer sale), we do not know the true price. All that we know is that the true price exceeds the ask price for an informed buy and is below the bid price for an informed sell. Consequently, in the estimation of regression model (12), we allow the true price to have a premium from one percent to ten percent over the option's exercise price. The results are reported in Panel B of Table 4.

The results reported in the Panel $\mathrm{B}$ of Table 4 are interesting in a number of respects. First, as the insider's "true" price rises relative to the exercise price, the probability that the trade was executed by an insider falls. This stands to reason since the product of the probability of an informed trade and the insider inventory-holding premium is nearly constant, as we discussed in Section II. Second, once $I H P_{I}$ is six percent in the money, the adjusted R-squared value reaches its maximum value of .7801. What this indicates is that, while we should be comfortable with models in which $I H P_{I}$ is at least six percent in the money, we cannot partition the expected adverse selection cost into its probability of informed trading and expected loss from informed trading components. Third, over this maximal adjusted R-squared range, the estimate of the probability of an informed trade $\alpha_{4}$ is significant but has a value of less than one percent. When one considers how little informed trading that actually takes place in a single stock 
on any given day, the estimate seems plausible. ${ }^{21}$ Fourth, the coefficient $\alpha_{9}$ is significantly positive independent of the degree to which $I H P_{I}$ is in the money. The evidence indicates the probability of informed trading rose after the introduction of Regulation FD.

Tables 3 and 4 are based on a comparison of spreads five months before the implementation of Regulation FD and five months after. A potential problem with this approach is that the information flow is averaged across the months in each sub-period. In reality, information flow is liable to have a seasonal behavior as a result of reporting activities such as quarterly earnings announcements. Consequently, to test the robustness of our results, we compare spreads in months separated by a quarter. Two of the comparisons straddle the month in which Regulation FD was implemented-August 2000 vs. November 2000 and September 2000 vs. December 2000. Two of the comparisons are on either side-June 2000 vs. September 2000 and November 2000 vs. February 2001. If Regulation FD affected the adverse information component of spread, there should be a significant difference detected in the first two comparisons but not in the second. The percent ITM of the $I H P_{I}$ is set equal to ten percent. Table 5 contains a summary of the results. Focusing on the coefficient $\alpha_{9}$, we see that the probability of informed trading increased significantly in the quarter to quarter comparisons that straddle the implementation of Regulation FD, and stayed the same in the quarter to quarter comparisons on either side. While this evidence should not be viewed as being independent of the results reported in Table 4, it corroborates the notion that Regulation FD has affected information flow.

The significance of the coefficient $\alpha_{9}$ in the regression results of Table 3 allow us to conclude the probability of informed trading has increased significantly. It also allows us to estimate the dollar size of the increase in the expected cost of adverse selection. Indeed, we can figure out the relative size of each of the cost components of the spread before and after Regulation FD to determine whether there has been an effect by

\footnotetext{
${ }^{21}$ Presumably, inside information is extraordinary and has a material effect on share price (e.g., a firm discovers that it has become a takeover target). For a typical firm in our sample, the number of such events is very small.
} 
computing the average value of each of the independent variables in the regression, multiplying by its respective coefficient, and then dividing by the average spread. Table 6 contains the results. As the table shows, there has been a shift in the weighting assigned to each cost category. Focusing on the results that maximize adjusted R-squared (rows in which $I T M \geq 6$ percent), we see that order processing costs are about 11-12 percent of the volume-weighted effective spread and did not change much after Regulation FD. The premium attached to competition, however, increased from about 2.5 percent of the spread to about 7 percent. Inventory-holding costs are the single largest cost component of spread, and fell in the post-Regulation FD sub-period. The adverse selection component rose from about 63/4 percent to about 103/4 percent of the volume-weighted effective spread. In dollar terms, this amounts to $.0675 \times \$ .1323$ or $\$ .00893$ per share preRegulation FD and $.1075 \times \$ .1143$ or $\$ .01229$ post—an increase of 38 percent.

The evidence in Table 6 suggests that Regulation FD did, in fact, have a chilling effect, causing inside information to become more valuable and long-lived and market makers to demand greater adverse selection risk premium.

\section{SUMMARY}

Regulation FD, imposed by the Securities and Exchange Commission (SEC) in October 2000, was designed to create a level playing field by prohibiting selective disclosure of material private information to particular groups such as analysts. Exactly what advantage analysts gain is unclear. If multiple insiders receive identical information, the information is immediately incorporated in price and the expected profit of each insider is zero. Regardless of the SEC's motivation in imposing Regulation FD, empirical investigation has shown that it has had a chilling effect, with firms now disclosing less information. With less information flow, private information becomes more long-lived and valuable. With increased risk of providing immediacy to informed traders, market makers will demand increased compensation, widening the bid/ask spread. To test this proposition, we identify the cost components of the bid/ask spread for a sample of NASDAQ stocks in the period just before and just after the implementation of Regulation 
FD. The evidence indicates that Regulation FD has led to an increase in the expected cost of the adverse selection component of the spread. 


\section{References}

Admati, A.R., and P. Pleiderer. 1988. A theory of intraday patterns: Volume and price variability. Review of Financial Studies 1, 3-40.

Agrawal, A. and S. Chadha. 2002. Who is afraid of Reg FD? The behavior and performance of sell-side analysts following the SEC's fair disclosure rules. Working paper, University of Alabama.

Aslan, H. 2002. The effect of Regulation Fair Disclosure on the information environment. Working paper, Cornell University.

Association for Investment Management and Research (AIMR). 2000. Press Release: August 11.

Association for Investment Management and Research (AIMR). 2001. FD e-Survey

summary. Downloaded on 17 June 2003 from:

http://www.aimr.com/pressroom/01releases/regfd_surveysum.htm

Bailey, W., H. Li, C.X. Mao and R. Zhong. 2003. Regulation Fair Disclosure and earnings information: Market, analyst, and corporate responses. Journal of Finance 58 (6), 2487-2514.

Black, F. and M. Scholes. 1973. The pricing of options and corporate liabilities, Journal of Political Economy 81, 637-659.

Bollen, N.P., T. Smith and R.E. Whaley. 2004. Modeling the bid/ask spread: Measuring the inventory-holding premium. Journal of Financial Economics 72, 97-141.

Brown, P., S.L. Taylor, and T.S. Walter. 1999. The impact of statutory sanctions on the level and information content of voluntary corporate disclosure, ABACUS 35 (2), 138162.

Council of Institutional Investors. 2000. Correspondence with SEC Chairman Levitt.

Easley, D., N. Kiefer, M. O’Hara and J. Paperman. 1996. Liquidity, information, and infrequently traded stocks. Journal of Finance 51 (4), 1405-1436.

Eleswarapu, V.R., R. Thompson and K. Venkataraman. 2003. The impact of Regulation Fair Disclosure: Trading costs and information asymmetry. Journal of Financial and Quantitative Analysis (forthcoming).

Foster, F.D. and Viswanathan, S. 1996. Strategic trading when agents forecast the forecasts of others. Journal of Finance 51, 1437-1478.

Gadarowski, C. and Sinha, P. 2003. On the efficacy of Regulation Fair Disclosure: Theory and evidence, Working paper, Rowan University and the University of Michigan - Flint.

Heflin, F., K.R. Subramanyam and Y. Zhang. 2003a. Regulation FD and the financial information environment: Early evidence. The Accounting Review 78 (1), 1-37.

Heflin, F., K.R. Subramanyam and Y. Zhang. 2003b. Stock return volatility before and after Regulation FD. Working paper, University of Southern California, Los Angeles. 
Holden, C.W. and Subrahmanyam, A. 1992. Long-lived private information and imperfect competition. Journal of Finance 47, 247-270.

Huang, R. and H. Stoll. 1996. Dealer versus auction markets: A paired comparison of execution costs on NASDAQ and NYSE. Journal of Financial Economics 41, 313-357.

Huang R.D. and Stoll H.R. 1997. The components of the bid-ask spread: A general approach” The Review of Financial Studies 10(4), 995-1034.

Irani, A. J. and I. Karamanou. 2003. Regulation Fair Disclosure, analyst following, and analyst forecast dispersion. Accounting Horizons 17 (1),15-29.

Merton, R.C. 1973. Theory of rational option pricing, Bell Journal of Economics and Management Science 4, 141-183.

Mohanram, P. and S. Sunder. 2001. Has Regulation Fair Disclosure affected financial analysts’ ability to forecast earnings? Working paper, New York University.

PricewaterhouseCoopers. 2001. Top executives say 'best' analysts focus more on fundamentals than forecasts. Management Barometer. August 14.

Richardson, S., S. Teoh and P. Wysocki. 2004. The walkdown to beatable analyst forecasts: The roles of equity issuance and insider trading incentives. Contemporary Accounting Research (forthcoming).

Securities and Exchange Commission. 2000a. Selective Disclosure and Insider Trading. Release Nos. 33-7881, 34-43154.

Securities and Exchange Commission. 2000b. Opening statement of Chairman Arthur Levitt. Open meeting on Regulation Fair Disclosure. 10 August.

Shane, P., N. Soderstrom and S.W. Yoon. 2001. Earnings and price discovery in the postReg. FD information environment: A preliminary analysis. Working paper, University of Colorado at Boulder.

Sunder, S.V. 2002. Investor access to conference call disclosures: Impact of Regulation Fair Disclosure on information asymmetry. Working paper, Northwestern University.

Straser, V. 2002. Regulation Fair Disclosure and information asymmetry. Working paper, University of Notre Dame.

Weber, J. 2000. Full disclosure for all web allows corporations to share information quickly and cheaply. Business Week. September 18:106. 
Table 1. Simulated probability of informed trade given percent premium of true price over ask price for informed traders. Stock price is set equal to $\$ 27.50$, bid/ask spread is $\$ .10$, and the volatility rate is 50 percent. Spread is assumed to be equal to

$$
S P R D=\left(1-p_{I}\right) I H P_{U}+p_{I} I H P_{I},
$$

where $p_{I}\left(1-p_{I}\right)$ is the probability of an informed (uniformed) trade, and $I H P_{I}\left(I H P_{U}\right)$ is the expected inventory holding premium for informed (uninformed) trades. $I H P_{U}$ is an out-of-themoney call option with the stock price equal to the bid/ask midpoint and an exercise price equal to the ask price. $I H P_{I}$ is an in-the-money call option with an exercise price equal to the ask price, and a stock price equal to the exercise price plus a "Percent ITM" premium. 
Table 2. Summary of descriptive statistics of variables used in the cross-sectional regressions of spreads for NASDAQ stocks. EWQS is the equal-weighted quoted bid/ask spread; VWES is the volume-weighted effective bid/ask spread; REWQS and RVWES are the equal-weighted quoted and volume-weighted effective bid/ask spreads divided by share price, respectively; $S$ is the share price; TV is the number of shares traded in thousands; $N D$ is the number of dealers; $M H I$ is the modified Herfindahl index; $\sigma$ is the annualized return volatility of the stock computed over the most recent sixty trading days prior to the estimation month; $\overline{\sqrt{t}}$ is the average of the square root of the number of minutes between trades; and IHP is expected inventory-holding premium as defined by

$$
I H P=S[2 N(.5 \sigma \overline{\sqrt{t}})-1]
$$

To be included in the sample, the stock must have traded at least five times each day in every day during the month. The sub-periods are the five months before and the five months after the imposition of Regulation FD in October 2000.

\begin{tabular}{|c|c|c|c|c|c|c|c|c|}
\hline \multirow[b]{3}{*}{ Variable } & \multicolumn{4}{|c|}{ Pre-Regulation FD } & \multicolumn{4}{|c|}{ Post-Regulation FD } \\
\hline & \multicolumn{4}{|c|}{$\begin{array}{c}\text { Period: May } 2000 \text { - September } 2000 \\
\text { No. of observations }=8,706\end{array}$} & \multicolumn{4}{|c|}{$\begin{array}{c}\text { Period: November } 2000 \text { - March } 2001 \\
\text { No. of observations = 7,568 }\end{array}$} \\
\hline & Mean & $25 \%$ & Median & $75 \%$ & Mean & $25 \%$ & Median & $75 \%$ \\
\hline \multicolumn{9}{|l|}{ Spread measures } \\
\hline EWQS & 0.1814 & 0.1004 & 0.1465 & 0.2208 & 0.1515 & 0.0852 & 0.1252 & 0.1843 \\
\hline VWQS & 0.1323 & 0.0772 & 0.1076 & 0.1577 & 0.1143 & 0.0681 & 0.0948 & 0.1360 \\
\hline REWQS & 0.0181 & 0.0069 & 0.0128 & 0.0238 & 0.0217 & 0.0064 & 0.0125 & 0.0267 \\
\hline RVWES & 0.0136 & 0.0050 & 0.0093 & 0.0178 & 0.0170 & 0.0049 & 0.0095 & 0.0207 \\
\hline \multicolumn{9}{|l|}{ Determinants of spread } \\
\hline$S$ & 21.64 & 5.65 & 13.41 & 28.11 & 17.48 & 4.44 & 12.13 & 25.06 \\
\hline$T V$ & 449.74 & 47.22 & 106.93 & 280.97 & 688.22 & 47.50 & 119.38 & 322.67 \\
\hline$N D$ & 89.06 & 43 & 67 & 110 & 79.41 & 33.75 & 56 & 97 \\
\hline MHI & 0.1194 & 0.0772 & 0.1077 & 0.1454 & 0.1076 & 0.0666 & 0.0941 & 0.1306 \\
\hline$\square$ & 0.9063 & 0.6222 & 0.8531 & 1.1426 & 1.0073 & 0.6495 & 0.9362 & 1.2629 \\
\hline Sqrt $t$ & 1.285 & 0.668 & 1.179 & 1.829 & 1.227 & 0.598 & 1.088 & 1.793 \\
\hline IHP & 0.0181 & 0.0071 & 0.0129 & 0.0231 & 0.0144 & 0.0056 & 0.0109 & 0.0187 \\
\hline
\end{tabular}


Table 3. Summary of cross-sectional regression results of absolute quoted and effective bid/ask spreads of NASDAQ stocks. EWQS $S_{i}$ is the equal-weighted quoted spread of stock $i, V W E S_{i}$ is the volume-weighted effective spread, $I n v T V_{i}$ is the inverse of the number of shares traded, $M H I$ is the modified Herfindahl index, and $I H P_{i}$ is the expected inventory-holding premium. The value of each variable, except $I H P_{i}$ and $M H I$, is computed each trading day, and then the values are averaged across all days during the month. All months during the five-month period preceding Regulation FD (May 2000 through September 2000) and during the five-month period after Regulation FD (November 2000 through March 2001) are included. The value of $I H P_{i}$ is computed using

$$
I H P_{i}=S_{i}\left[2 N\left(.5 \sigma_{i} \overline{\sqrt{t_{i}}}\right)-1\right]
$$

where $S_{i}$ is the average share price, $\sigma_{i}$ is the annualized return volatility of the stock computed over the most recent sixty trading days prior to the estimation month, and $\overline{\sqrt{t_{i}}}$ is the average of the square root of the time between trades. To be included in the sample in a particular month, the stock must have traded at least five times each day in every day during the month. Panel A contains the regression results where the equal-weighted quoted spread is used as the dependent variable, and Panel B contains the results for the volume-weighted effective spread. The Bollen-Smith-Whaley regression specification is

$$
B S W: S P R D_{i}=\alpha_{0}+\alpha_{1} I n v T V_{i}+\alpha_{2} M H I_{i}+\alpha_{3} I H P_{i}+\varepsilon_{i},
$$

and the ad hoc regression specification is

$$
\text { Ad hoc: } \operatorname{SPRD}_{i}=\alpha_{0}+\alpha_{1} \operatorname{InvTV}_{i}+\alpha_{2} M H I_{i}+\alpha_{3} S_{i}+\alpha_{4} \sigma_{i}+\alpha_{5} \bar{t}_{i}+\varepsilon_{i} .
$$




\begin{tabular}{|c|c|c|c|c|c|c|c|c|c|}
\hline \multirow[b]{2}{*}{ Period } & \multirow[b]{2}{*}{ Model } & \multirow{2}{*}{$\begin{array}{c}\text { No. of } \\
\text { obs. }\end{array}$} & \multirow{2}{*}{$\begin{array}{c}\text { Adjusted } \\
R \text {-squared }\end{array}$} & \multicolumn{6}{|c|}{ Coefficient estimates/t-ratios } \\
\hline & & & & $\hat{\alpha}_{0} / t\left(\hat{\alpha}_{0}\right)$ & $\hat{\alpha}_{1} / t\left(\hat{\alpha}_{1}\right)$ & $\hat{\alpha}_{2} / t\left(\hat{\alpha}_{2}\right)$ & $\hat{\alpha}_{3} / t\left(\hat{\alpha}_{3}\right)$ & $\hat{\alpha}_{4} / t\left(\hat{\alpha}_{4}\right)$ & $\hat{\alpha}_{5} / t\left(\hat{\alpha}_{5}\right)$ \\
\hline \multicolumn{10}{|c|}{ Panel A: Equal-weighted quoted spread } \\
\hline \multirow[t]{2}{*}{ Pre } & $B S W$ & 8,706 & 0.8049 & 0.0517 & 806.49 & 0.0122 & 6.3746 & & \\
\hline & & & & 14.12 & 9.82 & 0.62 & 32.02 & & \\
\hline \multirow[t]{2}{*}{ Post } & BSW & 7,568 & 0.7646 & 0.0419 & 788.08 & 0.0525 & 6.3376 & & \\
\hline & & & & 16.56 & 9.23 & 3.27 & 32.26 & & \\
\hline \multirow[t]{2}{*}{ Full } & BSW & 16,274 & 0.7923 & 0.0462 & 784.05 & 0.0362 & 6.3882 & & \\
\hline & & & & 20.14 & 11.73 & 2.58 & 42.09 & & \\
\hline \multirow[t]{2}{*}{ Pre } & Ad hoc & 8,706 & 0.4002 & 0.0344 & 3885.92 & 0.3636 & 0.0027 & 0.0189 & -541.33 \\
\hline & & & & 2.58 & 11.09 & 10.15 & 8.45 & 3.91 & -6.16 \\
\hline \multirow[t]{2}{*}{ Post } & Ad hoc & 7,568 & 0.5199 & 0.0394 & 3400.80 & 0.3319 & 0.0029 & -0.0052 & -377.31 \\
\hline & & & & 3.59 & 12.80 & 11.79 & 9.67 & -1.36 & -6.08 \\
\hline \multirow[t]{2}{*}{ Full } & Ad hoc & 16,274 & 0.4465 & 0.0375 & 3628.91 & 0.3722 & 0.0028 & 0.0032 & -464.89 \\
\hline & & & & 3.31 & 14.61 & 14.16 & 9.62 & 0.83 & -7.30 \\
\hline \multicolumn{10}{|c|}{ Panel B: Volume-weighted effective spread } \\
\hline \multirow[t]{2}{*}{ Pre } & $B S W$ & 8,706 & 0.7772 & 0.0412 & 786.57 & -0.0194 & 4.4632 & & \\
\hline & & & & 11.39 & 10.61 & -1.28 & 21.16 & & \\
\hline \multirow[t]{2}{*}{ Post } & $B S W$ & 7,568 & 0.7484 & 0.0347 & 708.98 & 0.0287 & 4.5269 & & \\
\hline & & & & 14.81 & 10.58 & 2.32 & 24.47 & & \\
\hline \multirow[t]{2}{*}{ Full } & BSW & 16,274 & 0.7682 & 0.0379 & 749.86 & 0.0042 & 4.4893 & & \\
\hline & & & & 16.37 & 13.57 & 0.39 & 28.10 & & \\
\hline \multirow[t]{2}{*}{ Pre } & Ad hoc & 8,706 & 0.4029 & 0.0290 & 3026.07 & 0.2335 & 0.0019 & 0.0140 & -415.80 \\
\hline & & & & 2.99 & 10.24 & 9.48 & 8.11 & 4.15 & -6.11 \\
\hline \multirow[t]{2}{*}{ Post } & Ad hoc & 7,568 & 0.5231 & 0.0324 & 2624.86 & 0.2341 & 0.0020 & -0.0032 & -292.39 \\
\hline & & & & 3.81 & 12.74 & 11.48 & 8.99 & -1.11 & -6.28 \\
\hline \multirow[t]{2}{*}{ Full } & Ad hoc & 16,274 & 0.4496 & 0.0315 & 2824.90 & 0.2479 & 0.0019 & 0.0029 & -361.06 \\
\hline & & & & 3.78 & 14.08 & 13.67 & 9.18 & 1.07 & -7.53 \\
\hline
\end{tabular}


Table 4. Summary of cross-sectional regression results of absolute effective bid/ask spreads of NASDAQ stocks. VWES ${ }_{i}$ is the volumeweighted effective spread, $I n v T V_{i}$ is the inverse of the number of shares traded, $M H I$ is the modified Herfindahl index, and $I H P_{i}$ is the expected inventory-holding premium. The value of each variable, except $I H P_{i}$ and $M H I$, is computed each trading day, and then the values are averaged across all days during the month. The value of $I H P_{i}$ is computed using

$$
I H P_{i}=S_{i}\left[2 N\left(.5 \sigma_{i} \overline{\sqrt{t_{i}}}\right)-1\right]
$$

where $S_{i}$ is the average share price, $\sigma_{i}$ is the annualized return volatility of the stock computed over the most recent sixty trading days prior to the estimation month, and $\overline{\sqrt{t_{i}}}$ is the average of the square root of the time between trades. To be included in the sample, the stock must have traded at least five times each day in every day during the month. All months during the five-month period preceding Regulation FD (May 2000 through September 2000) and during the five-month period after Regulation FD (November 2000 through March 2001) are included. The regression model is

$$
\begin{aligned}
V_{W E S}= & \alpha_{0}+\alpha_{1} \operatorname{InvTV}_{i}+\alpha_{2} M H I_{i}+\alpha_{3} I H P_{U, i}\left(\tau_{i}\right)+\alpha_{4}\left(I H P_{I, i}\left(\tau_{i}\right)-I H P_{U, i}\left(\tau_{i}\right)\right) \\
& +\alpha_{5} d_{t}+\alpha_{6} \operatorname{InvTV}_{i} d_{t}+\alpha_{7} M H I_{i} d_{t}+\alpha_{8} I H P_{U, i}\left(\tau_{i}\right) d_{t}+\alpha_{9}\left(I H P_{I, i}\left(\tau_{i}\right)-I H P_{U, i}\left(\tau_{i}\right)\right) d_{t}+\varepsilon_{i}
\end{aligned},
$$

where $I H P_{U, i}$ is the expected inventory-holding premium for trades with uninformed traders and $I H P_{I, i}$ is the expected inventory-holding premium for trades with informed traders. For a trade at the ask, the value of $I H P_{k, i}$ is computed using

$$
I H P_{k, i}=S_{k, i} N\left(\frac{\ln \left(S_{k, i} / X_{i}\right)}{\sigma_{i} \sqrt{t_{i}}}+.5 \sigma_{i} \overline{\sqrt{t_{i}}}\right)-X_{i} N\left(\frac{\ln \left(S_{k, i} / X_{i}\right)}{\sigma_{i} \sqrt{t_{i}}}-.5 \sigma_{i} \overline{\sqrt{t_{i}}}\right) .
$$

$I H P_{U, i}$ is valued as an out-of-the-money call option with an exercise price equal to the ask price and a stock price equal to the bid/ask midpoint. $I H P_{I, i}$ is valued as an in-the-money (ITM) call option with an exercise price equal to the ask price and a stock price Percent ITM above the exercise price. For a trade at the bid, the IHP is valued using a put option formula with an exercise price equal to the bid price. 


\begin{tabular}{|c|c|c|c|c|c|c|c|c|c|c|c|c|}
\hline \multirow{2}{*}{$\begin{array}{c}\text { Percent } \\
\text { ITM }\end{array}$} & \multirow{2}{*}{$\begin{array}{c}\text { No. of } \\
\text { obs. }\end{array}$} & \multirow{2}{*}{$\begin{array}{c}\text { Adjusted } \\
\text { R-squared }\end{array}$} & \multicolumn{10}{|c|}{ Coefficient estimates/t-ratios } \\
\hline & & & $\hat{\alpha}_{0} / t\left(\hat{\alpha}_{0}\right)$ & $\hat{\alpha}_{1} / t\left(\hat{\alpha}_{1}\right)$ & $\hat{\alpha}_{2} / t\left(\hat{\alpha}_{2}\right)$ & $\hat{\alpha}_{3} / t\left(\hat{\alpha}_{3}\right)$ & $\hat{\alpha_{4} / t\left(\hat{\alpha}_{4}\right)}$ & $\hat{\alpha}_{5} / t\left(\hat{\alpha}_{5}\right)$ & $\hat{\alpha}_{6} / t\left(\hat{\alpha}_{6}\right)$ & $\hat{\alpha}_{7} / t\left(\hat{\alpha}_{7}\right)$ & $\hat{\alpha}_{8} / t\left(\hat{\alpha}_{8}\right)$ & $\hat{\alpha}_{9} / t\left(\hat{\alpha}_{9}\right)$ \\
\hline \multicolumn{13}{|c|}{ Panel A: Single composite inventory-holding premium } \\
\hline & 16,274 & 0.7685 & 0.0412 & 786.56 & -0.0194 & 4.4632 & -0.0065 & -77.56 & 0.0481 & 0.0637 & & \\
\hline & & & 11.39 & 10.67 & -1.28 & 21.18 & -1.61 & -0.85 & 2.72 & 0.24 & & \\
\hline \multicolumn{13}{|c|}{ Panel B: Separate inventory-holding premia for uninformed and informed traders } \\
\hline \multirow[t]{2}{*}{1} & 16274 & 0.6690 & 0.0357 & 1267.90 & 0.0653 & 1.0921 & 0.0951 & -0.0114 & 46.70 & 0.0525 & -0.1597 & 0.0497 \\
\hline & & & 8.43 & 12.62 & 3.10 & 12.80 & 8.59 & -2.35 & 0.36 & 2.34 & -1.58 & 3.86 \\
\hline \multirow[t]{2}{*}{2} & 16274 & 0.7796 & 0.0303 & 905.30 & 0.0252 & 0.9419 & 0.0218 & -0.0077 & -33.36 & 0.0490 & -0.0274 & 0.0144 \\
\hline & & & 10.28 & 11.87 & 1.50 & 17.55 & 6.78 & -2.01 & -0.34 & 2.53 & -0.42 & 3.28 \\
\hline \multirow[t]{2}{*}{3} & 16274 & 0.7798 & 0.0302 & 908.57 & 0.0256 & 0.9378 & 0.0144 & -0.0078 & -31.27 & 0.0493 & -0.0314 & 0.0097 \\
\hline & & & 10.49 & 11.88 & 1.51 & 17.14 & 6.50 & -2.05 & -0.31 & 2.52 & -0.48 & 3.21 \\
\hline \multirow[t]{2}{*}{4} & 16274 & 0.7799 & 0.0301 & 909.92 & 0.0257 & 0.9350 & 0.0108 & -0.0078 & -30.09 & 0.0495 & -0.0340 & 0.0074 \\
\hline & & & 10.59 & 11.88 & 1.51 & 16.89 & 6.36 & -2.07 & -0.30 & 2.52 & -0.51 & 3.19 \\
\hline \multirow[t]{2}{*}{5} & 16274 & 0.7800 & 0.0301 & 910.54 & 0.0259 & 0.9332 & 0.0086 & -0.0078 & -29.41 & 0.0496 & -0.0357 & 0.0059 \\
\hline & & & 10.64 & 11.88 & 1.51 & 16.74 & 6.29 & -2.08 & -0.29 & 2.52 & -0.53 & 3.19 \\
\hline \multirow[t]{2}{*}{6} & 16,274 & 0.7801 & 0.0301 & 910.84 & 0.0259 & 0.9318 & 0.0072 & -0.0079 & -28.96 & 0.0497 & -0.0368 & 0.0050 \\
\hline & & & 10.67 & 11.88 & 1.51 & 16.64 & 6.26 & -2.09 & -0.29 & 2.52 & -0.55 & 3.19 \\
\hline \multirow[t]{2}{*}{7} & 16274 & 0.7801 & 0.0301 & 911.01 & 0.0260 & 0.9308 & 0.0062 & -0.0079 & -28.72 & 0.0497 & -0.0376 & 0.0043 \\
\hline & & & 10.67 & 11.88 & 1.52 & 16.58 & 6.25 & -2.09 & -0.29 & 2.52 & -0.56 & 3.19 \\
\hline \multirow[t]{2}{*}{8} & 16274 & 0.7801 & 0.0301 & 911.11 & 0.0260 & 0.9300 & 0.0054 & -0.0079 & -28.59 & 0.0498 & -0.0382 & 0.0037 \\
\hline & & & 10.68 & 11.88 & 1.52 & 16.53 & 6.24 & -2.09 & -0.29 & 2.52 & -0.57 & 3.19 \\
\hline \multirow[t]{2}{*}{9} & 16274 & 0.7801 & 0.0301 & 911.17 & 0.0260 & 0.9294 & 0.0048 & -0.0079 & -28.52 & 0.0497 & -0.0387 & 0.0033 \\
\hline & & & 10.68 & 11.88 & 1.52 & 16.50 & 6.24 & -2.09 & -0.29 & 2.52 & -0.57 & 3.19 \\
\hline \multirow[t]{2}{*}{10} & 16274 & 0.7801 & 0.0301 & 911.19 & 0.0260 & 0.9289 & 0.0043 & -0.0079 & -28.46 & 0.0497 & -0.0390 & 0.0030 \\
\hline & & & 10.68 & 11.88 & 1.52 & 16.47 & 6.24 & -2.10 & -0.28 & 2.52 & -0.58 & 3.19 \\
\hline
\end{tabular}


Table 5. Summary of cross-sectional regression results of absolute quoted and effective bid/ask spreads of NASDAQ stocks. VWES ${ }_{i}$ is the volume-weighted effective spread, $I n v T V_{i}$ is the inverse of the number of shares traded, $M H I$ is the modified Herfindahl index, and $I H P_{i}$ is the expected inventory-holding premium. The value of each variable, except $I H P_{i}$ and $M H I$, is computed each trading day, and then the values are averaged across all days during the month. All months during the five-month period preceding Regulation FD (May 2000 through September 2000) and during the five-month period after Regulation FD (November 2000 through March 2001) are included. The regression specification is

$$
\begin{aligned}
V_{W E S}= & \alpha_{0}+\alpha_{1} \operatorname{InvTV}_{i}+\alpha_{2} M H I_{i}+\alpha_{3} I H P_{U, i}\left(\tau_{i}\right)+\alpha_{4}\left(I H P_{I, i}\left(\tau_{i}\right)-I H P_{U, i}\left(\tau_{i}\right)\right) \\
& +\alpha_{5} d_{t}+\alpha_{6} \operatorname{InvTV}_{i} d_{t}+\alpha_{7} M H I_{i} d_{t}+\alpha_{8} I H P_{U, i}\left(\tau_{i}\right) d_{t}+\alpha_{9}\left(I H P_{I, i}\left(\tau_{i}\right)-I H P_{U, i}\left(\tau_{i}\right)\right) d_{t}+\varepsilon_{i}
\end{aligned}
$$

where $d_{t}$ is a dummy variable whose value is 0 in months preceding October 2001 and 1 in months after October 2001. $I H P_{U, i}$ is the expected inventory-holding premium for trades with uninformed traders and $I H P_{I, i}$ is the expected inventory-holding premium for trades with informed traders. The value of $I H P_{k, i}$ is computed using

$$
I H P_{k, i}=S_{k, i} N\left(\frac{\ln \left(S_{k, i} / X_{i}\right)}{\sigma_{i} \sqrt{t_{i}}}+.5 \sigma_{i} \overline{\sqrt{t_{i}}}\right)-X_{i} N\left(\frac{\ln \left(S_{k, i} / X_{i}\right)}{\sigma_{i} \sqrt{t_{i}}}-.5 \sigma_{i} \overline{\sqrt{t_{i}}}\right),
$$

where $\sigma_{i}$ is the annualized return volatility of the stock computed over the most recent sixty trading days prior to the estimation month, $\overline{\sqrt{t_{i}}}$ is the average of the square root of the time between trades. $I H P_{U, i}$ is valued as an out-of-the-money call option with an exercise price equal to the ask price and a stock price equal to the bid/ask midpoint. $I H P_{I, i}$ is valued as a ten percent in-the-money (ITM) call option with an exercise price equal to the ask price and a stock price. 
First Second No. of Adjusted

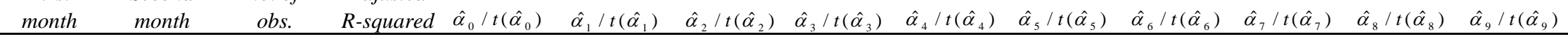
Panel A: Three months apart and surrounding intervention month

Aug-00 Nov-00 $\quad 3,215 \quad 0.6748$

$\begin{array}{cc}0.0414 & 1367.42 \\ 7.73 & 10.03\end{array}$

$0.0253 \quad 1.056$

1.0561
10.56

0.0148

$-0.0081$

252.48

$0.0410 \quad 1062.24$

0.66

6.20

$-1.85$

1.39

0.0625

$0.0355 \quad 0.0078$

Sep-00

Dec-00

3,292

0.6796

7.24

6.61

1.0856

0.0133

$-0.0045$

691.32

$-0.0206$

$-0.52$

$-0.0548$

$-0.29$

2.85

Panel B: Three months apart and on either side of intervention month

$\begin{array}{lc}9.05 & 7.44\end{array}$

1.0411

0.0170

0.0030

26100

0.0497

0.1891

0.0081

Nov-00 Feb-

$3,023-0.6708$

$0.0336 \quad 1659.17$

0.0908

12.20

8.45

0.44

$-1.14$

1.34

1.52

$-0.0029$

.

$7.56 \quad 10.86$

3.34

1.1978
6.18

0.0236
7.27

-0.0022
-0.47

-703.22
-4.13

$-0.0313$

$-0.3494$

$-1.79$

$-0.0035$

$-1.02$ 
Table 6. Summary of cost components of absolute effective bid/ask spreads of NASDAQ stocks. The notation is defined as follows: $V W E S_{i}$ is the volume-weighted effective spread, $I n v T V_{i}$ is the inverse of the number of shares traded, $M H I$ is the modified Herfindahl index , and $I H P_{i}$ is the expected inventory holding premium. The value of each variable, except $I H P_{i}$ and MHI, is computed each trading day and then the values are averaged across all days during the month. To be included in the sample, the stock must have traded at least five times each day in every day during the month. The estimates are for the regression,

$$
S P R D_{i}=\alpha_{0}+\alpha_{1} I n v T V_{i}+\alpha_{2} M H I_{i}+I H P_{U, i}\left(\tau_{i}\right)+\alpha_{4}\left(I H P_{I, i}\left(\tau_{i}\right)-I H P_{U, i}\left(\tau_{i}\right)\right)+\varepsilon_{i},
$$

where $I H P_{U, i}$ is the expected inventory holding premium for trades with uninformed traders and $I H P_{I, i}$ is the expected inventory holding premium for trades with informed traders. The regression is run in both the pre period (May 2000 - September 2000) and the post period (November 2000 - March 2001). Cost components are computed using the method outlined in Bollen, Smith and Whaley (2003).

\begin{tabular}{|c|c|c|c|c|c|}
\hline $\begin{array}{c}\text { Percent } \\
\text { ITM }\end{array}$ & $\begin{array}{c}\text { Minimum } \\
\text { tick } \\
\text { size }\end{array}$ & $\begin{array}{c}\text { Order } \\
\text { processing } \\
\text { costs }\end{array}$ & Competition & $\begin{array}{l}\text { Inventory } \\
\text { holding } \\
\text { costs }\end{array}$ & $\begin{array}{c}\text { Adverse } \\
\text { selection } \\
\text { costs }\end{array}$ \\
\hline \multirow[t]{2}{*}{1} & $26.97 \%$ & $15.46 \%$ & $5.89 \%$ & $37.26 \%$ & $14.41 \%$ \\
\hline & $21.23 \%$ & $18.32 \%$ & $11.08 \%$ & $28.72 \%$ & $20.65 \%$ \\
\hline \multirow[t]{2}{*}{2} & $22.91 \%$ & $11.04 \%$ & $2.27 \%$ & $57.80 \%$ & $5.98 \%$ \\
\hline & $19.77 \%$ & $12.15 \%$ & $6.98 \%$ & $51.78 \%$ & $9.33 \%$ \\
\hline \multirow[t]{2}{*}{3} & $22.81 \%$ & $11.08 \%$ & $2.31 \%$ & $57.55 \%$ & $6.25 \%$ \\
\hline & $19.60 \%$ & $12.22 \%$ & $7.05 \%$ & $51.32 \%$ & $9.81 \%$ \\
\hline \multirow[t]{2}{*}{4} & $22.77 \%$ & $11.10 \%$ & $2.32 \%$ & $57.38 \%$ & $6.42 \%$ \\
\hline & $19.51 \%$ & $12.26 \%$ & $7.08 \%$ & $51.02 \%$ & $10.13 \%$ \\
\hline \multirow[t]{2}{*}{5} & $22.75 \%$ & $11.11 \%$ & $2.33 \%$ & $57.27 \%$ & $6.54 \%$ \\
\hline & $19.46 \%$ & $12.28 \%$ & $7.10 \%$ & $50.82 \%$ & $10.34 \%$ \\
\hline \multirow[t]{2}{*}{6} & $22.74 \%$ & $11.11 \%$ & $2.34 \%$ & $57.18 \%$ & $6.63 \%$ \\
\hline & $19.43 \%$ & $12.29 \%$ & $7.12 \%$ & $50.68 \%$ & $10.49 \%$ \\
\hline \multirow[t]{2}{*}{7} & $22.73 \%$ & $11.11 \%$ & $2.34 \%$ & $57.12 \%$ & $6.69 \%$ \\
\hline & $19.41 \%$ & $12.29 \%$ & $7.12 \%$ & $50.57 \%$ & $10.60 \%$ \\
\hline \multirow[t]{2}{*}{8} & $22.73 \%$ & $11.11 \%$ & $2.34 \%$ & $57.08 \%$ & $6.74 \%$ \\
\hline & $19.40 \%$ & $12.30 \%$ & $7.13 \%$ & $50.50 \%$ & $10.68 \%$ \\
\hline \multirow[t]{2}{*}{9} & $22.72 \%$ & $11.11 \%$ & $2.35 \%$ & $57.04 \%$ & $6.78 \%$ \\
\hline & $19.40 \%$ & $12.30 \%$ & $7.13 \%$ & $50.44 \%$ & $10.74 \%$ \\
\hline \multirow[t]{2}{*}{10} & $22.72 \%$ & $11.11 \%$ & $2.35 \%$ & $57.01 \%$ & $6.81 \%$ \\
\hline & $19.40 \%$ & $12.30 \%$ & $7.13 \%$ & $50.39 \%$ & $10.78 \%$ \\
\hline
\end{tabular}

